\title{
Optimasi Algoritme Nä̈ve Bayes untuk Klasifikasi Data Gempa Bumi di Indonesia Berdasarkan Hiposentrum
}

\author{
Rastri Prathivi \\ Teknik Informatika \\ Fakultas Teknologi Informasi dan Komunikasi \\ Universitas Semarang \\ Email : vivi@usm.ac.id
}

\section{N F O A R T I K E L}

Sejarah Artikel:

Menerima 21 November 2019

Revisi 13 Januari 2020

Received 27 Februari 2020

Online 29 Februari 2020

\section{Keyword:}

Earthquake Classification

Hypocenter

Adaboost

Naïve Bayes

\section{Kata Kunci:}

Klasifikasi Gempa

Hiposentrum

Adaboost

Naïve Bayes

\section{Korespondensi:}

Telepon: +62 085950251065

E-mail: vivi@usm.ac.id

\begin{abstract}
The Hiposentrum or epicentre is the source of an earthquake which is at a certain depth on earth. The classification of earthquake powers based on the depth of Hiposentrum needed to examine the potential earthquake powers spread in Indonesian territory. The results of the classification process often experience problems, namely inaccuracy in classification. To solve that problem, then algorithms optimising classification must be increased. This research uses the Nä̈ve Bayes algorithm, which is optimized using the Adaboost algorithm. Evaluation of the results of the optimized classification algorithm is needed to determine the level of accuracy using prescriptions and recall. In this study, the object of research is earthquake data in Indonesia which will be used as training data and testing data. The average accuracy of the Nä̈ve Bayes algorithm is $72.3 \%$, and the Nä̈ve Bayes and Adaboost algorithm is $85.3 \%$.
\end{abstract}

\begin{tabular}{l} 
ABSTRAK \\
\hline Hiposentrum atau pusat gempa merupakan sumber gempa yang terdapat pada \\
kedalaman tertentu di bumi. Klasifikasi kekuatan gempa berdasarkan kedalaman \\
hiposentrum diperlukan untuk mengetahui potensi kekuatan gempa yang tersebar \\
di wilayah Indonesia. Hasil dari proses klasifikasi seringkali mengalami masalah \\
yaitu ketidaktepatan dalam klasifikasi. Untuk mengatasi masalah tersebut maka \\
algoritme klasifikasi perlu ditingkatkan optimasinya. Penelitian ini menggunakan \\
algoritme Nä̈ve Bayes yang dioptimasi menggunakan algoritme Adaboost. \\
Evaluasi terhadap hasil dari algoritme klasifikasi yang telah dioptimasi \\
diperlukan untuk mengetahui tingkat akurasi menggunakan presicion dan recall. \\
Dalam penelitian ini objek penelitian berupa data gempa bumi di Indonesia yang \\
akan digunakan sebagai data training dan data testing. Hasil rata - rata akurasi \\
algoritme Nä̈ve Bayes sebesar 72,3\% dan algoritme Nä̈ve Bayes dan Adaboost \\
sebesar 85,3\%.
\end{tabular}

\section{PENDAHULUAN}

Hiposentrum atau pusat gempa merupakan sumber gempa yang terdapat pada kedalaman tertentu di bumi. Kekuatan suatu gempa sangat tergantung pada lokasi hiposentrumnya. Menurut Hartuti (2009) klasifikasi gempa berdasarkan hiposentrumnya diklasifikasikan menjadikan tiga bagian yaitu gempa bumi dalam adalah gempa bumi yang terjadi dengan kedalaman hiposentrum $>300 \mathrm{~km}$ di bawah permukaan bumi. Gempa bumi menengah yaitu gempa bumi yang terjadi dengan kedalaman hiposentrum berkisar antara $60 \mathrm{~km}$ sampai $300 \mathrm{~km}$ di bawah permukaan bumi. Gempa bumi dangkal yaitu gempa bumi yang terjadi dengan kedalaman hiposentrum $<60 \mathrm{~km}$ di bawah permukaan bumi. Berdasarkan letak wilayah geografisnya Indonesia adalah negara kepulauan yang memiliki potensi gempa bumi yang besar. 
Data pada Badan Meteorologi, Klimatologi dan Geofisika (BMKG) mencatat terjadinya gempa bumi di Indonesia secara berkala dalam selang waktu beberapa bulan saja. Bahkan potensi gempa bumi yang lokasi hiposentrumnya cukup dalam hampir terjadi setiap hari.

Klasifikasi kekuatan gempa berdasarkan kedalaman hiposentrum diperlukan untuk mengetahui potensi kekuatan gempa yang tersebar di wilayah Indonesia. Hasil dari proses klasifikasi seringkali mengalami masalah yaitu ketidaktepatan dalam klasifikasi. Untuk mengatasi masalah tersebut maka algoritme klasifikasi perlu ditingkatkan optimasinya. Menurut Saritas (saritas, 2019) algoritme Nä̈ve Bayes merupakan algoritme probabilitas sederhana untuk mengklasifikasikan data berdasarkan probabilitas data dengan menghitung frekuensi dan kombinasi nilai pada dataset yang digunakan. Di dalam algoritme Nä̈ve Bayes setiap data diasumsikan sebagai variabel bebas yang dapat mempertimbangkan nilai dari variabel klasifikasi. Pada penelitian yang dilakukan oleh Saritas (saritas 2019) performa akurasi algoritme Nä̈ve Bayes sebesar 83.54 terhadap algoritme ANN 86.95 yang digunakan untuk mengklasifikasikan data kanker payudara. Dalam penelitian yang ditemukan oleh Nakra (2019) algoritme Naïve Bayes memiliki tingkat akurasi yang cukup baik yaitu 79.6935 terhadap algoritme Bayes Net sebesar 78.5441 yang dihitung dengan tool WEKA. Dalam penelitian tersebut algoritme Nä̈ve Bayes masih dimungkinkan untuk ditingkatkan akurasinya dengan mengoptimasi algoritme Nä̈ve Bayes tersebut. Dalam penelitian ini penulis yang akan meningkatkan optimasi algoritme Nä̈ve Bayes yang diterapkan untuk mengklasifikasikan dataset gempa bumi berdasarkan hiposentrumnya. Untuk meningkatkan optimasi algoritme Naïve Bayes, penulis menggunakan algoritme Adaboost. Evaluasi terhadap hasil dari algoritme klasifikasi yang telah dioptimasi diperlukan untuk mengetahui tingkat akurasi menggunakan presicion dan recall. Dalam penelitian ini objek penelitian berupa data gempa bumi di Indonesia yang akan digunakan sebagai data training dan data testing. Berbagai penelitian yang terkait dengan klasifikasi kekuatan gempa dan lokasi gempa telah banyak dilakukan oleh para peneliti sebelumnya. Sari (2018) menggunakan algoritme K-AP Clustering untuk mengklasifikasikan gempa bumi di Indonesia. Fatichah (2017) mengklasifikasi data gempa berdasarkan data dari twitter menggunakan algoritme Decision Tree, Random Forest dan SVM. Halim (2017) mengelompokkan dampak gempa di Indonesia menggunakan algoritme Kohonen Self Organizing Maps (SOM). Saraswathi (2014) membuat komparasi beberapa algoritmeclustering untuk mendapatkan akurasi dari algoritme KMeans, DB Scan, Hirarki dan Optic.

\section{METODE PENELITIAN}

\section{Jenis dan Sumber Data}

Jenis data primer yang digunakan dalam penelitian ini adalah data gempa bumi tahun 2017 yang terdiri dari data terjadinya gempa. Sumber data dalam penelitian ini berasal dari Badan Meteorologi, Klimatologi dan Geofisik (BMKG) http://repogempa.bmkg.go.id/.

\section{Variabel Penelitian}

Variabel dalam penelitian ini dibagi menjadi tiga bagian atribut yaitu kedalaman hiposentrum, magnitudo dan lokasi gempa. Yang menjadi data primer dalam proses klasifikasi adalah data kedalaman hiposentrum. Data tersebut akan dibagi menjadi tiga klasifikasi yaitu gempa dalam, gempa menengah dan gempa dangkal. Data primer merupakan data utama yang digunakan sebagai acuan dalam suatu penelitian dan merupakan data yang diolah dalam suatu penelitian. Data 


\section{Analisa Data Penelitian}

Data primer yang digunakan dalam penelitian masih berupa data mentah yang belum diolah. Ada sekitar 6090 data yang digunakan dalam penelitian ini. Data mentah tersebut memiliki atribut yang datanya hilang (missing values) terutama pada atribut magnitudo. Jumlah atribut yang datanya hilang ada sekitar 3678 data. Data yang demikian perlu diolah atau dipreprocessing. Untuk melakukan preprocessing data menggunakan algoritme normalisasi data. Dataset dibagi menjadi dua bagian yaitu dataset sebagai data pelatihan (training) sebanyak 80\% dari 6090 data yaitu 4872 data. Sedangkan data uji (testing) sebanyak 20\% yaitu sebanyak 1218 data. Contoh data gempa terlihat pada Tabel 1.

Tabel 1. Contoh data gempa di Indonesia

\begin{tabular}{|c|c|c|c|c|c|c|c|c|c|c|}
\hline $\begin{array}{c}\text { Data } \\
k e-\end{array}$ & $\begin{array}{l}\text { Tan } \\
\text { ggal }\end{array}$ & $\begin{array}{c}\text { Waktu } \\
(\text { WIB }= \\
\text { UTC + } \\
7 \text { Jam })\end{array}$ & $\begin{array}{l}\text { Hip } \\
\text { osen } \\
\text { trum }\end{array}$ & Mag & $\begin{array}{l}\text { Type } \\
\text { Mag }\end{array}$ & smaj & smin & $a z$ & $r m s$ & Region \\
\hline 1 & $\begin{array}{r}1 / 1 / \\
2017 \\
\end{array}$ & 13:25.9 & 76 & 5 & MLv & 62.78 & 0.96 & 160 & 1.415 & $\begin{array}{l}\text { Northern } \\
\text { Molucca Sea }\end{array}$ \\
\hline 2 & $\begin{array}{r}1 / 1 / \\
2017 \\
\end{array}$ & 45:54.6 & 74 & 4 & MLv & 1.79 & 0.55 & 158 & 0.601 & $\begin{array}{l}\text { Near North } \\
\text { Coast of } \\
\text { Irian Jaya }\end{array}$ \\
\hline 3 & $\begin{array}{r}1 / 1 / \\
2017 \\
\end{array}$ & 58:13.7 & 10 & 4 & MLv & 7.68 & 1.16 & 210 & 0.894 & $\begin{array}{l}\text { Java, } \\
\text { Indonesia }\end{array}$ \\
\hline 4 & $\begin{array}{r}1 / 1 / \\
2017 \\
\end{array}$ & 05:01.1 & 533 & 4.2 & $\mathrm{mb}$ & 24.47 & 1.13 & 51 & 0.595 & Flores Sea \\
\hline 5 & $\begin{array}{r}1 / 1 / \\
2017 \\
\end{array}$ & 39:18.2 & 10 & 4.1 & MLv & 4.95 & 0.87 & 215 & 0.816 & $\begin{array}{l}\text { Southwest of } \\
\text { Sumatra, } \\
\text { Indonesia }\end{array}$ \\
\hline 6 & $\begin{array}{r}1 / 1 / \\
2017 \\
\end{array}$ & 12:09.8 & 66 & 5.1 & $\mathrm{mb}$ & 24.41 & 2.07 & 144 & 0.958 & $\begin{array}{l}\text { North of } \\
\text { Halmahera, } \\
\text { Indonesia }\end{array}$ \\
\hline 7 & $\begin{array}{r}1 / 1 / \\
2017 \\
\end{array}$ & 13:39.1 & 32 & 5.5 & $\begin{array}{l}\mathrm{Mw}( \\
\mathrm{mB})\end{array}$ & 84.39 & 2.03 & 126 & 1.342 & $\begin{array}{l}\text { North of } \\
\text { Halmahera, } \\
\text { Indonesia }\end{array}$ \\
\hline 8 & $\begin{array}{r}1 / 1 / \\
2017\end{array}$ & $17: 51.7$ & 10 & 4.8 & $\mathrm{mb}$ & 17.66 & 2.33 & 262 & 1.238 & $\begin{array}{l}\text { North of } \\
\text { Halmahera, } \\
\text { Indonesia }\end{array}$ \\
\hline 9 & $\begin{array}{r}1 / 1 / \\
2017 \\
\end{array}$ & 13:39.4 & 10 & 4.4 & $\mathrm{mb}$ & 12.43 & 2.1 & 242 & 0.545 & $\begin{array}{l}\text { North of } \\
\text { Halmahera, } \\
\text { Indonesia }\end{array}$ \\
\hline 10 & $\begin{array}{r}1 / 1 / \\
2017 \\
\end{array}$ & 27:23.9 & 63 & 1.8 & MLv & 1.71 & 0.44 & 101 & 0.225 & $\begin{array}{l}\text { Minahassa } \\
\text { Peninsula, } \\
\text { Sulawesi } \\
\end{array}$ \\
\hline 11 & $\begin{array}{r}1 / 1 / \\
2017\end{array}$ & $36: 49.8$ & 10 & 3.5 & MLv & 4.01 & 1.01 & 213 & 0.416 & $\begin{array}{l}\text { South of } \\
\text { Bali, } \\
\text { Indonesia }\end{array}$ \\
\hline 12 & $\begin{array}{r}1 / 1 / \\
2017 \\
\end{array}$ & $25: 16.8$ & 15 & 3 & MLv & 2 & 0.95 & 270 & 0.318 & $\begin{array}{l}\text { Southwest of } \\
\text { Sumatra, } \\
\text { Indonesia }\end{array}$ \\
\hline 13 & $\begin{array}{r}1 / 1 / \\
2017 \\
\end{array}$ & $46: 40.7$ & 21 & 2.9 & MLv & 4.25 & 0.68 & 268 & 0.107 & $\begin{array}{l}\text { Sumbawa } \\
\text { Region, } \\
\text { Indonesia }\end{array}$ \\
\hline 14 & $\begin{array}{r}1 / 1 / \\
2017 \\
\end{array}$ & $01: 15.3$ & 14 & 2.7 & MLv & 3.27 & 1.43 & 157 & 0.092 & $\begin{array}{l}\text { Sulawesi, } \\
\text { Indonesia }\end{array}$ \\
\hline 15 & $\begin{array}{r}1 / 1 / \\
2017 \\
\end{array}$ & 18:52.1 & 293 & 3.7 & MLv & 6.76 & 0.47 & 72 & 0.685 & Bali Sea \\
\hline 16 & $\begin{array}{r}1 / 1 / \\
2017\end{array}$ & $36: 03.7$ & 155 & 4.4 & $\mathrm{mb}$ & 9.38 & 1.41 & 210 & 0.851 & $\begin{array}{l}\text { North of } \\
\text { Halmahera, } \\
\text { Indonesia }\end{array}$ \\
\hline 17 & $\begin{array}{r}1 / 1 / \\
2017 \\
\end{array}$ & $45: 22.1$ & 10 & 3.5 & MLv & 4.09 & 0.1 & 59 & 1.128 & $\begin{array}{l}\text { Northern } \\
\text { Sumatra, } \\
\text { Indonesia }\end{array}$ \\
\hline 18 & $\begin{array}{r}1 / 1 / \\
2017 \\
\end{array}$ & 58:00.8 & 35 & 4.7 & $\mathrm{mb}$ & 53.59 & 1.89 & 144 & 0.982 & $\begin{array}{l}\text { Off West } \\
\text { Coast of }\end{array}$ \\
\hline
\end{tabular}




\begin{tabular}{|c|c|c|c|c|c|c|c|c|c|c|}
\hline $\begin{array}{c}\text { Data } \\
\text { ke- }\end{array}$ & $\begin{array}{l}\text { Tan } \\
\text { ggal }\end{array}$ & $\begin{array}{c}\text { Waktu } \\
(\text { WIB }= \\
\text { UTC + } \\
7 \text { Jam })\end{array}$ & $\begin{array}{l}\text { Hip } \\
\text { osen } \\
\text { trum }\end{array}$ & Mag & $\begin{array}{l}\text { Type } \\
\text { Mag }\end{array}$ & smaj & $\operatorname{smin}$ & $a z$ & $r m s$ & Region \\
\hline & & & & & & & & & & $\begin{array}{l}\text { Northern } \\
\text { Sumatra } \\
\end{array}$ \\
\hline 19 & $\begin{array}{r}1 / 2 / \\
2017 \\
\end{array}$ & $56: 50.3$ & 10 & 2.9 & MLv & 1.35 & 0.76 & 247 & 0.466 & $\begin{array}{l}\text { Southern } \\
\text { Sumatra, } \\
\text { Indonesia }\end{array}$ \\
\hline 20 & $\begin{array}{r}1 / 2 / \\
2017 \\
\end{array}$ & 52:57.9 & 87 & 4.9 & $\mathrm{mb}$ & 16.06 & 1.41 & 79 & 0.819 & Banda Sea \\
\hline
\end{tabular}

\section{Tahapan Penelitian}

Berikut tahapan penelitian yang dilakukan oleh penulis, terlihat pada Gambar 1.

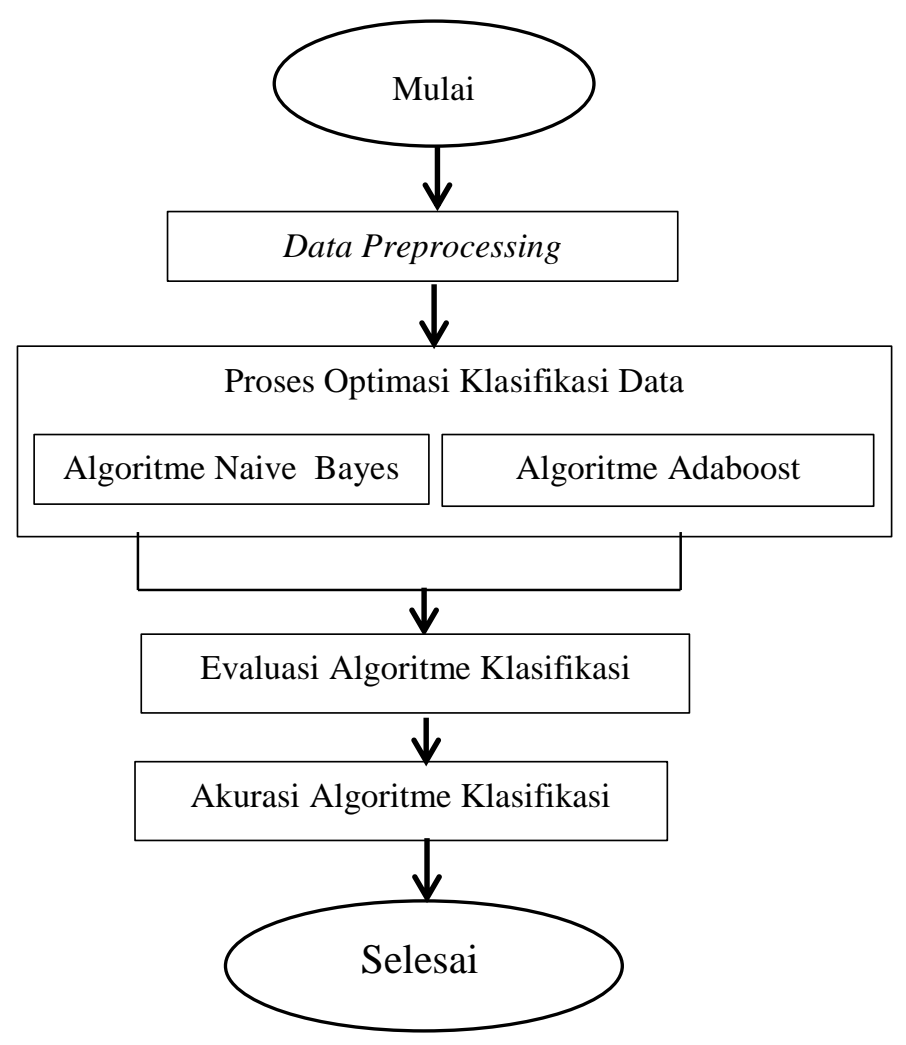

Gambar 1. Tahapan Penelitian

a. Data Preprocessing

Pada proses ini untuk data yang hilang atau missing value perlu dilakukan pembersihan data atau data cleaning. Pada data preprocessing ini data yang mengalami pengulangan record atau redundansi dinormalisasi.

b. Proses Klasifikasi Data

Proses klasifikasi data menggunakan algoritme Naïve Bayes dengan rumus

c. Optimasi

Data yang sudah dinormalisasi kemudian diklasifikasi dengan algoritme Nä̈ve Bayes dan dioptimasi dengan algoritme Adaboost.

Algoritme Nä̈ve Bayes terdiri dari beberapa tahap yaitu:

1. Menghitung jumlah kelas yang akan diklasifikasikan

2. Menghitung jumlah kasus dari setiap kelas

3. Kalikan dengan varian variabel yang telah ditentukan 
4. Bandingkan hasilnya pada setiap kelas

Konsep dasar dari algoritme Adaboost adalah memberikan bobot yang lebih pada klasifikasi yang tidak tepat (weak classification). Boosting bisa dikombinasi dengan classifier algoritme lainnya untuk menambah performa klasifikasi (Listiana, 2017). Tahapan dalam algoritme Adaboost (Listiana, 2017) yaitu:

1. Input: Suatu kumpulan dataset penelitian dengan label $\left\{\left(\mathrm{x}_{\mathrm{i}}, \mathrm{y}_{\mathrm{i}}\right)\left(\mathrm{x}_{\mathrm{N}}, \mathrm{y}_{\mathrm{N}}\right)\right\}$, suatu component learn algoritme, jumlah perputaran $\mathrm{T}$.

2. Inisialisasi: Bobot $\left\{\mathrm{w}_{\mathrm{i}}\right\}$ data training $w_{i}^{1}=1 / N$ untuk semua $\mathrm{i}=1, \ldots, \mathrm{N}$

3. Iterasi for $\mathrm{m}=1, \ldots, \mathrm{M}$

a. Gunakan component learn algoritme untuk melatih suatu komponen klasifikasi, $\mathrm{y}_{\mathrm{m}}$, pada bobot data pelatihan. Cocokkan clasifier $y_{m}\left(x_{i}\right)$ dengan data pelatihannya untuk meminimalisir bobot fungsi eror pada:

$$
\mathrm{J}_{\mathrm{m}}=\sum_{i=1}^{N} w_{i}^{m} I, y_{m}\left(x_{i}\right) \neq t_{n}
$$

dimana $I\left(y_{m}\left(x_{i}\right) \neq t_{n}\right)$ sebagai fungsi indikator akan bernilai 1

ketika $y_{m}\left(x_{i}\right) \neq t_{n}$ dan 0 untuk $y_{m}\left(x_{i}\right)=t_{n}$

b. Evaluasi kuantitas

$$
\varepsilon_{\mathrm{m}}=\frac{\sum_{i=1}^{N} w_{i}^{m} I, y_{m}\left(x_{i}\right) \neq t_{n}}{\sum_{i=1}^{N} w_{i}^{m}}
$$

Gunakan persamaan 2. untuk mengevaluasi persamaan 3.

$$
\alpha_{m}=\ln \left\{\frac{1-\varepsilon_{m}}{\varepsilon_{m}}\right\}
$$

c. Update koefisien bobot

$w_{i}^{(m+1)}=\frac{w_{i}^{(m)} \exp \left\{\alpha_{m} I\left(y_{m}\left(x_{i}\right) \neq t_{n}\right)\right\}}{C_{m}}$

dengan $C_{m}$ adalah konstanta untuk normalisasi

d. Output:

$$
Y_{M}(x)=\operatorname{sign}\left(\sum_{m=1}^{M} \alpha_{m} y_{m}(x)\right)
$$

d. Evaluasi Algoritme Klasifikasi

Metode klasifikasi Nä̈ve Bayes yang sudah dioptimasi pada data hiposentrum gempa dievaluasi menggunakan algoritme confusion matrix.

Pada penelitian ini klasifikasi dibagi menjadi tiga kelas maka ada cara menghitung akurasi, presisi dan recall dapat dilakukan dengan menghitung rata-rata dari nilai akurasi, presisi dan recall pada setiap kelas.

$$
\text { Akurasi }=\frac{T P_{i}+T N_{i}}{T P_{i}+T N_{i}+F P_{i}+F N_{i}} \times 100 \%
$$

dimana:

- $\quad \mathrm{TP}_{i}$ adalah True Positive, yaitu jumlah data positif yang terklasifikasi dengan benar oleh sistem untuk kelas ke-i.

- $\quad T N_{i}$ adalah True Negative, yaitu jumlah data negatif yang terklasifikasi dengan benar oleh sistem untuk kelas ke-i. 
- $F N_{i}$ adalah False Negative, yaitu jumlah data negatif namun terklasifikasi salah oleh sistem untuk kelas ke-i.

- $\quad F P_{i}$ adalah False Positive, yaitu jumlah data positif namun terklasifikasi salah oleh sistem untuk kelas ke-i

e. Akurasi AlgoritmeKlasifikasi

Akurasi dari algoritmeoptimasi Nä̈ve Bayes menggunakan precision dan recall.

$$
\begin{gathered}
\text { Precision }=\frac{\sum_{i=1}^{l} T P_{i}}{\sum_{i=1}^{l}\left(F P_{i}+T P_{i}\right)} * 100 \%(7) \\
\text { Recall }=\frac{\sum_{i=1}^{l} T P_{i}}{\sum_{i=1}^{l}\left(F P_{i}+F N_{i}\right)} * 100 \%(8)
\end{gathered}
$$

\section{HASIL DAN PEMBAHASAN}

\section{Hasil dari Preprocessing Data menggunakan proses normalisasi}

(Z-Transformation) dan replace missing values. Normalisasi yang dilakukan adalah normalisasi pada atribut magnitudo dengan hasil normalisasi mean: 4.047947569271616, variance: 113.84787442937836. Untuk hasil replace missing values dengan menambahkan data dengan perhitungan rata-rata (average) pada atribut magnitudo.

\section{Hasil klasifikasi gempa bumi dan evaluasi algoritme klasifikasi}

Hasil klasifikasi gempa bumi terlihat pada tabel 1 berdasarkan data testing yang diujikan yaitu sebanyak total 1218 data. Gempa dangkal hiposentrumnya kurang dari $60 \mathrm{~km}$, gempa sedang hiposentrumnya antara $60 \mathrm{~km}$ sampai $300 \mathrm{~km}$ dan gempa dalam memiliki hiposentrum lebih dari $300 \mathrm{~km}$. Akurasi yang dihitung adalah akurasi dari hasil klasifikasi yaitu akurasi gempa dangkal, sedang dan dalam. Algoritme yang digunakan untuk menghitung akurasi menggunakan algoritme confusion matrix.

Perhitungan akurasi dari setiap metode Nä̈ve Bayes dan Nä̈ve Bayes + Adaboost dapat dilihat pada Tabel 2 sampai dengan Tabel 7.

Tabel 2. Akurasi Gempa Dangkal dengan Nä̈ve Bayes Banyak Gempa $=214$

\begin{tabular}{ccc}
\hline & $\begin{array}{c}\text { Predicted } \\
\text { False }\end{array}$ & $\begin{array}{c}\text { Predicted } \\
\text { True }\end{array}$ \\
\hline Actual False & $\mathrm{TN}=38$ & $\mathrm{FP}=37$ \\
\hline Actual True & $\mathrm{FN}=29$ & $\mathrm{TP}=110$ \\
\hline Akurasi $=$ & $69 \%$ & \\
\hline
\end{tabular}

Tabel 3. Akurasi Gempa Sedang dengan Naïve Bayes Banyak Gempa $=998$

\begin{tabular}{lll}
\hline & $\begin{array}{l}\text { Predicted } \\
\text { False }\end{array}$ & $\begin{array}{l}\text { Predicted } \\
\text { True }\end{array}$ \\
\hline Actual False & TN=96 & FP=99 \\
\hline Actual True & FN=89 & TP $=714$ \\
\hline Akurasi $=$ & \multicolumn{2}{c}{$81 \%$} \\
\hline
\end{tabular}


Tabel 4. Akurasi Gempa Dalam dengan Nä̈ve Bayes Banyak Gempa 6

\begin{tabular}{lll}
\hline & $\begin{array}{l}\text { Predicted } \\
\text { False }\end{array}$ & $\begin{array}{l}\text { Predicted } \\
\text { True }\end{array}$ \\
\hline Actual False & TN=1 & FP=2 \\
\hline Actual True & FN=0 & TP $=3$ \\
\hline Akurasi $=$ & \multicolumn{3}{c}{$67 \%$} \\
\hline
\end{tabular}

Tabel 5. Akurasi Gempa Dangkal dengan Optimasi Nä̈ve Bayes dan Adaboost Banyak Gempa $=119$

\begin{tabular}{lll}
\hline & $\begin{array}{l}\text { Predicted } \\
\text { False }\end{array}$ & $\begin{array}{l}\text { Predicted } \\
\text { True }\end{array}$ \\
\hline Actual False & $\mathrm{TN}=23$ & $\mathrm{FP}=13$ \\
\hline Actual True & $\mathrm{FN}=7$ & $\mathrm{TP}=76$ \\
\hline Akurasi $=$ & \multicolumn{2}{c}{$83 \%$} \\
\hline
\end{tabular}

Tabel 6. Akurasi Gempa Sedang dengan Optimasi Nä̈ve Bayes dan Adaboost Banyak Gempa $=1093$

\begin{tabular}{lll}
\hline & $\begin{array}{l}\text { Predicted } \\
\text { False }\end{array}$ & $\begin{array}{l}\text { Predicted } \\
\text { True }\end{array}$ \\
\hline Actual False & $\mathrm{TN}=110$ & $\mathrm{FP}=11$ \\
\hline Actual True & $\mathrm{FN}=96$ & $\mathrm{TP}=876$ \\
\hline \multicolumn{3}{c}{$90 \%$} \\
\hline Akurasi $=$ & \multicolumn{2}{c}{$90 \%$} \\
\hline
\end{tabular}

Tabel 7. Akurasi Gempa Dalam dengan Optimasi Nä̈ve Bayes dan Adaboost Banyak Gempa $=6$

\begin{tabular}{lll}
\hline & $\begin{array}{l}\text { Predicted } \\
\text { False }\end{array}$ & $\begin{array}{l}\text { Predicted } \\
\text { True }\end{array}$ \\
\hline Actual False & $\mathrm{TN}=2$ & $\mathrm{FP}=1$ \\
\hline Actual True & $\mathrm{FN}=0$ & $\mathrm{TP}=3$ \\
\hline Akurasi $=$ & \multicolumn{3}{c}{$83 \%$} \\
\hline
\end{tabular}

Tabel 8. Jumlah Lokasi Berdasarkan Klasifikasi Hiposentrum Gempa Bumi

\begin{tabular}{|c|c|c|c|c|c|c|c|}
\hline $\begin{array}{l}\text { Algoritme } \\
\text { Klasifikasi }\end{array}$ & $\begin{array}{l}\text { Gempa } \\
\text { Dangkal }\end{array}$ & $\begin{array}{l}\text { Akurasi } \\
\text { Gempa } \\
\text { Dangkal }\end{array}$ & $\begin{array}{l}\text { Gempa } \\
\text { Sedang }\end{array}$ & $\begin{array}{l}\text { Akurasi } \\
\text { Gempa } \\
\text { Sedang }\end{array}$ & $\begin{array}{l}\text { Gempa } \\
\text { Dalam }\end{array}$ & $\begin{array}{l}\text { Akurasi } \\
\text { Gempa } \\
\text { Dalam }\end{array}$ & $\begin{array}{l}\text { Rata- } \\
\text { Rata }\end{array}$ \\
\hline $\begin{array}{l}\text { Nä̈ve } \\
\text { Bayes }\end{array}$ & 214 & $69 \%$ & 998 & $81 \%$ & 6 & $67 \%$ & $72,3 \%$ \\
\hline $\begin{array}{l}\text { Nä̈ve Bayes } \\
+ \text { Adaboost }\end{array}$ & 119 & $83 \%$ & 1093 & $90 \%$ & 6 & $83 \%$ & $85,3 \%$ \\
\hline
\end{tabular}




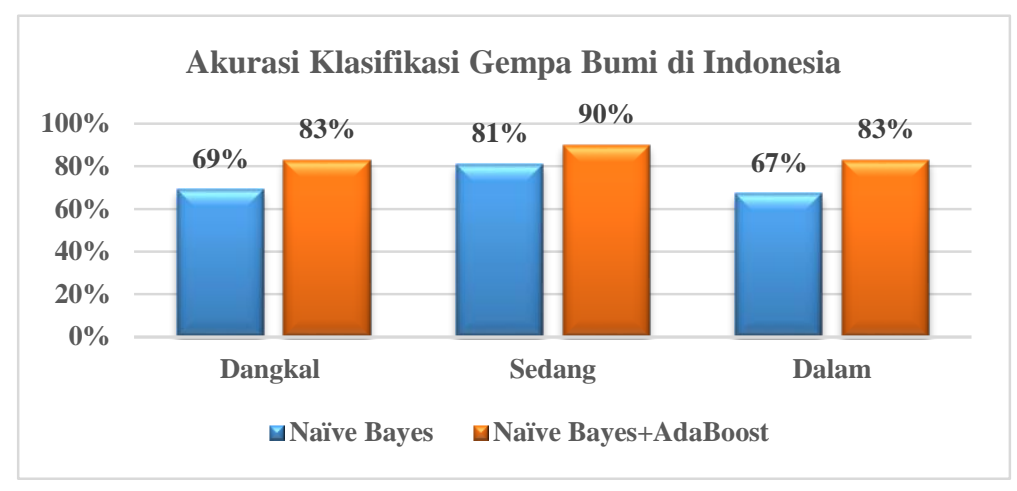

Gambar 2. Hasil Akurasi Setiap Klasifikasi Gempa

Pada Gambar 2. Disimpulkan bahwa hasil rata - rata akurasi algoritme Nä̈ve Bayes sebesar 72,3\% dan optimasi algoritme Nä̈ve Bayes dan Adaboost sebesar 85,3\%

\section{KESIMPULAN DAN SARAN}

Kesimpulan dan saran dari penelitian ini adalah Hasil rata - rata akurasi algoritme Nä̈ve Bayes sebesar 72,3\% dan algoritme Nä̈ve Bayes dan Adaboost sebesar 85,3\%. Dari hasil klasifikasi terlihat bahwa jumlah lokasi yang paling banyak terjadi gempa bumi adalah lokasi gempa bumi sedang sebanyak 1093 lokasi. Penelitian ini juga bisa dikembangkan untuk klasfikasi data gempa yang berpotensi tsunami dan dengan menggunakan algoritme clustering untuk mengelompokkan gempa bumi berdasarkan bagian wilayah Indonesia.

\section{DAFTAR PUSTAKA}

Chengsheng, T., Huacheng, L., \& Bing, X. (2017). Adaboost typical Algorithm and its application research. In MATEC Web of Conferences (Vol. 139, p. 00222). EDP Sciences.

Dey, L., Chakraborty, S., Biswas, A., Bose, B., \& Tiwari, S. (2016). Sentiment analysis of review datasets using Nä̈ve Bayes and k-nn classifier. arXiv preprint arXiv:1610.09982.

E. Prasetyo, (2012) Data Mining: Konsep dan Aplikasi menggunakan Matlab, 1 ed. Yogyakarta: Andi Offset.

Fatichah, C., \& Purwitasari, D. (2017). Deteksi Gempa Berdasarkan Data Twitter Menggunakan Decision Tree, Random Forest, dan SVM. Jurnal Teknik ITS, 6(1), 153-158.

Haixiang, G., Yijing, L., Yanan, L., Xiao, L., \& Jinling, L. (2016). BPSO-Adaboost-KNN ensemble learning algorithm for multi-class imbalanced data classification. Engineering Applications of Artificial Intelligence, 49, 176-193.

Halim, N. N., \& Widodo, E. (2017). Clustering Dampak Gempa Bumi di Indonesia Menggunakan Kohonen Self Organizing Maps (SOM). In Prosiding SI MaNIs (Seminar Nasional Integrasi Matematika dan Nilai-Nilai Islami) (Vol. 1, No. 1, pp. 188-194).

Hartuti, E. R. 2009. Buku Pintar Gempa. Yogyakarta: Diva Perss

Listiana, E., \& Muslim, M. A. (2017). Penerapan Adaboost untuk Klasifikasi Support Vector Machine Guna Meningkatkan Akurasi pada Diagnosa Chronic Kidney Disease. Prosiding SNATIF, 875-881.

Nakra, A., \& Duhan, M. (2019). Comparative Analysis of Bayes Net Classifier, Nä̈ve Bayes Classifier and Combination of both Classifiers using WEKA. IJ Inf. Technol. Comput. Sci, 11, 38-45.

Saraswathi, S., \& Sheela, M. I. (2014). A comparative study of various clustering algorithms in data mining. International Journal of Computer Science and Mobile Computing, 11(11), 422-428.

Sari, N. N. (2018). K-Affinity Propagation (K-AP) Clustering Untuk Klasifikasi Gempa Bumi (Studi Kasus: Gempa Bumi di Indonesia Tahun 2017).

Saritas, M. M., \& Yasar, A. (2019). Performance Analysis of ANN and Nä̈ve Bayes Classification Algorithm for Data Classification. International Journal of Intelligent Systems and Applications in Engineering, 7(2), 88-91. 